Check for updates

Sheffield, UK

Cite this as: $B M J$ 2021;375:n2466 http://dx.doi.org/10.1136/bmj.n2466 Published: 08 October 2021

\title{
NHS in England on track to hit first year carbon reduction target
}

\section{Emma Wilkinson}

The NHS is on track to meet its target to become a carbon net zero health service by 2045, one year after it announced its intention.

Presenting data from the first 12 months of the programme at the NHS board, ${ }^{1}$ head of sustainability Nick Watts said he expected to cut total emissions in 2021-22 by 1260 kilotonnes of carbon dioxide equivalent (ktCO2e), just ahead of the target that was set.

The reduction, which is the equivalent to emissions from 1.1 million homes or 1.7 million flights from London to New York and back, is largely down to direct action to reduce emissions, government action to decarbonise the national grid, and the response to the covid-19 pandemic, he said.

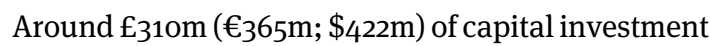
in renewable energy, efficiency measures, and lighting upgrades is expected to produce a $210 \mathrm{ktCO} 2 \mathrm{e}$ reduction in 2021-22. The report gives examples of 2500 solar panels on Milton Keynes University Hospital and the installation of heat pumps at Gloucestershire Hospital NHS Foundation Trust.

An expected $112 \mathrm{ktCO}$ e reduction should come from switching to green vehicles with plans for the world's first electric ambulances able to supply both urban and rural populations to be announced within weeks, Watts said.

The pandemic has also led to substantial changes in staff behaviour around travel. Oxford University Hospitals NHS Foundation Trust are now using e-bike couriers to deliver cancer treatments to their hospital sites, the report outlined. Hospitals have also gone further than expected on cutting the use of desflurane anaesthetic. And the primary care impact and investment fund will incentivise reductions of carbon emissions from inappropriate inhaler use, said Watts.

Some emissions had increased because of the pandemic-including expanded use of personal protective equipment and heating, ventilation, and air conditioning in covid vaccination programme sites. But overall an interim analysis suggests a neutral impact.

The NHS also reiterated its "clear expectations" that between now and 2030 suppliers will need to get on board with the zero net carbon strategy. Setting out the timetable, Watts said that from April 2022, 10\% of all procurement decisions will need to consider a net zero weighting.

NHS England chief executive Amanda Pritchard said, "It's a massive achievement to be able to say that the NHS is on track to deliver its planned cut in emissions this financial year. The effects of poor air quality and climate change are already being seen in our GP practices, in our hospitals, and unfortunately in our mortuaries too.
"There's no doubt that this is a long term problem for the NHS and it's right that we are part of the solution. But we can't do this alone and that's why it's so important we throw down the gauntlet to our suppliers."

Watts said that a recent survey showed nine out of 10 staff were supportive of the NHS goals on sustainability.

Andy Haines, professor of environmental change and public health at the London School of Hygiene and Tropical Medicine, said the NHS strategy was "the right level of ambition, very wide ranging, and has the support of NHS staff."

He congratulated the team on the work so far but he said decarbonising the supply chain would be crucial. "It's going to be important to ensure they fulfil their commitments and not just through offsetting but through real cuts in emissions," he said.

"It's important the NHS is seen as a pioneer, not just as an end in itself but as an example of what can be done and as a way of leading much larger social change."

Director of the UK Health Alliance on Climate Change Elaine Mulcahy said, "We welcome the progress that has been made by NHS England to reduce its carbon footprint in line with the targets set one year ago. The NHS is one of the largest employers in the world and contributes almost $5 \%$ of UK carbon emissions. By taking direct action to reduce emissions and work towards resilient, low carbon, sustainable health systems, it sets an example to others while also benefiting the health of those it seeks to care for."

Dodge I, Watts N, Bailie P. Delivering a net zero NHS-one year progress. October 2021. www.england.nhs.uk/wp-content/uploads/2021/09/item4 delivering-net-zero-nhs-updated.pdf. 